\title{
Farklı Yeşil Budama Uygulamalarının Merlot (Vitis vinifera L.) Üzüm Çeşidinde Tane Olgunluğu Üzerine Etkileri
}

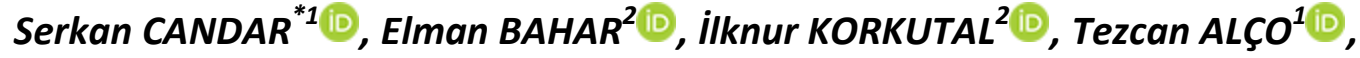 Mehmet GÜLCÜ3}

\author{
${ }^{1}$ Tekirdağ Bağcılık Araştırma Enstitüsü, Yetiştirme Tekniği Bölümü \\ ${ }^{2}$ Tekirdağ Namık Kemal Üniversitesi Bahçe Bitkileri Bölümü \\ ${ }^{3}$ Tekirdağ Bağcılık Araştırma Enstitüsü, Gıda Teknolojileri Bölümü
}

Öz: Bu çalışma, 2013-2015 yılları arasında Tekirdağ Bağcılık Araştırma Enstitüsü bağlarında, 13 yaşındaki Merlot/5BB asmalarda koltuk sürgünleri (Yok, 3-4 yaprak, 6-7 yaprak) ve ana sürgünlerde $(1 \mathrm{~m}, 1.25 \mathrm{~m}, 1.5 \mathrm{~m}$ ) yapılan farklı yeşil budama uygulamalarının tane olgunluğu ve bazı olgunluk indislerine olan etkilerinin incelenmesi amacıyla yapılmıştır. Özellikle koltuk sürgünü uygulamalarının, yetiştiricilik yapılan yılın iklim özelliklerine bağıı olarak, istenilen olgunluk indisini yakalayabilmek için suda çözünebilir kuru madde birikimini erkene çekme ya da geciktirme yönünde etkili olduğu belirlenmiştir. Bu süreçlerde yapılacak farklı yeşil budama uygulamalarında fenolojik dönem ve vejetasyonun iklim özellikleri belirleyici kriterler olarak değerlendirilmelidir.

Anahtar Kelimeler: taç yönetimi, SÇKM, olgunluk göstergeleri, Merlot

\section{The Effects of Different Green Pruning Applications on Berry Maturaton in Merlot (Vitis vinifera L.)}

\begin{abstract}
This study was carried out between 2013-2015 years in the vineyards of Tekirdağ Viticulture Research Institute, in order to examine the effects of different green pruning applications to lateral shoots (None, 3-4 leaves, 6-7 leaves) and to main shoots (1 m, $1.25 \mathrm{~m}$, $1.5 \mathrm{~m}$ ) on berry maturity and some maturity indexes on 13 years old Merlot/5BB vines. It has been determined that, especially lateral shoots applications are effective to closer or delay the desired maturity indices depending on the climate characteristics of the year. The phenological period and the climatic specifications of the vegetation should be considered as the determining criteria in the manipulations to be carried out in these processes.
\end{abstract}

Keywords: canopy management, TSS, maturity indicators, Merlot

\section{GiRiş}

Sıcaklık, asmanın büyüme ve gelişme süreçlerinin düzenlenmesinde rol alan en önemli faktördür. Küresel sıcaklıklar geçen yüzyılda ortalama 0.4-0.8 of artmıştır (Anonim, 2007). Yirmi birinci yüzyılın sonlarına doğru Türkiye'de 1-4 으 (Türkeş, 2002), küresel ortalamalarda ise sera gazı salınım seviyelerine de bağlı olmak üzere, 4-5 으 civarında sıcaklık artışı beklenmektedir (Anonim, 2013).

İtalya, Almanya ve Fransa gibi önemli şarap üreticisi ülkelerde ve dünyanın diğer bölgelerinde yapılan araştırmalar iklim değişikliği sürecinin geleceğe dönük bir beklenti olmaktan öte günümüzde yaşanmaya başladığını ortaya koymaktadır. Avrupa kıtasında yetiştirme dönemlerinin kısaldığı ve fenolojik aşamaların daha erken meydana geldiği (Chuine ve ark., 2004; Jones ve ark., 2005; Dalla ve ark., 2010; Bock ve ark., 2011; Daux ve ark., 2012) görülmekte; benzer değişiklikler Avusturalyalı araştırıcılar tarafından da desteklenmektedir (Webb ve ark., 2011; Sadras ve Petrie, 2011).

Fenolojik süreçlerin bu denli erken ve hızlı gerçekleşmesi olgunlaşmanın hızlanmasına ve şarap kalitesi üzerinde olumsuz etkilere neden olmaktadır (Webb ve ark., 2008). Önolojik olgunluğun dengeli biçimde gerçekleşmesi için endüstriyel, fenolik ve aromatik olgunlukların aynı ölçüde dengeli süreçlerle ortaya çıkması gerekir.

Sıcaklığa bağlı nedenler ile tanede aşırı şeker birikiminin şaraptaki alkol miktarını fazla yükseltmesi (Godden ve Gishen, 2005; Petrie ve Sadras, 2008), asitliğin çok düşmesi (Vrsic ve Vodovnik, 2012), yüksek pH ve şarapta tip dışı aromaların ortaya çıkması (Bahar ve ark., 2012; Poni ve ark., 2013; Palliotti ve ark., 2013; Parker ve ark., 2016) gibi birçok olumsuzluk bağcılık ve şarapçılık profesyonellerini düşündüren konular olarak ortaya çıkmaktadır.

$\mathrm{Bu}$ süreçlerin yönetilmesinde düşük maliyetle ve hızlıca uygulanabilir olması nedeniyle farklı taç yönetimi uygulamalarının önemi birçok çalışmada vurgulanmıştır (Olsen ve ark., 2011; Bahar ve ark., 2018)

Bu çalışmada farklı yaprak alanı azaltma işlemleri uygulanan Merlot çeşidi asmalarda, yeşil budama uygulamalarının

Sorumlu Yazar: serkan.candar@tarimorman.gov.tr Bu çalışma doktora tez ürünüdür ve T.C Tarım ve Orman Bakanlığı, Tarımsal Araştırmalar ve Politikalar Genel Müdürlüğü tarafından TAGEM/BBAD/2013/A08/P04-08 numaralı proje ile desteklenmiştir.

Geliş Tarihi: 1 Şubat 2019

Kabul Tarihi: 1 Temmuz 2019 
farklı iklim özelliği gösteren 3 yılda endüstriyel olgunluk bileşenleri ve endüstriyel olgunluğu nasıl etkilediği araştırılmıştır.

\section{MATERYAL ve YÖNTEM}

\section{Materyal}

Çalışma Merlot/5BB aşı kombinasyonu asmalarda 20132015 yılları arasında yürütülmüştür. Asmalara duvar sisteminde Guyot (çift kollu) terbiye şekli verilmiştir. Gövde yüksekliği $60 \mathrm{~cm}$ olup, yatırma teli ile 1 . bağlama teli arasındaki mesafe $60 \mathrm{~cm} ; 1$. bağlama teli ile 2 . bağlama teli arasındaki mesafe $40 \mathrm{~cm}$ 'dir. Denemenin yürütüldüğü yıllarda bitkilerin yaşı 11-13 arasında değişmiştir. Deneme Tekirdağ Bağcılık Araştırma Enstitüsü araştırma parsellerinde $40^{\circ} 58^{\prime} \mathrm{K}$ ile $27^{\circ} 28^{\prime} \mathrm{D}$ koordinatlarındaki bağlarda kurulmuştur. Bağın dikim yönü Kuzey-Güney olup, düz zemindedir. Deneme parseline ait $0-30 \mathrm{~cm}, 30-60 \mathrm{~cm}$ ve 60-90 cm derinliğindeki toprak analizleri sonucunda; killitınlı bünyede, pH tüm toprak derinliklerinde hafif alkali, tuzluluk bakımından tuzsuz, kireçli sınıfa girmekle birlikte; birikiminin $\quad 60-90 \mathrm{~cm}$ toprak derinliğinde olduğu görülmüştür. Organik madde bakımından da az derin toprak tabakasında yetersiz sınıfta yer almaktadır.

\section{Yöntem}

Denemede koltuk sürgünü uygulamaları; tüm yaprakları alınmış koltuk sürgünü (Yok), dipten 3-4 yaprağı üzerinde bırakılmış koltuk sürgünü (3-4 yaprak), ve dipten 6 - 7 yaprağı üzerinde bırakılmış koltuk sürgünü (6-7 yaprak) uygulamalarından oluşmuştur. Ana sürgün uygulamalarında ise yazlık sürgünler $1 \mathrm{~m}, 1.25 \mathrm{~m}$ ve $1.5 \mathrm{~m}$ uzunluklarından sınırlandırılmıştır. Koltuk sürgünü uygulamaları Lorenz ve ark. (1995)'e göre ben düşme döneminde (EL 35), ana sürgün uygulamaları da sürgün uzunlukları $170-180 \mathrm{~cm}$ civarına ulaştığı dönemde (EL 31-33) yapılmış ve hasat sonuna kadar bu yaprak alanları korunmuştur.

Her 3 yılda da kış budamalarında 16 göz üzerinden budama yapılmış, buna rağmen asmalarda gelişme farklılıkları görülmüş ise salkım ve sürgün sayıları $30-40 \mathrm{~cm}$ civarına ulaştığında (EL 15-17) müdahaleler yapılarak asmalar arasında tekdüzelik sağlanmıştır.

Araştırma süresince tüm parsellerde yetiştiricilik uygulamaları standart olarak uygulanmıştır. Olgunluk üzerinde görülebilecek değişkenliğin verimden kaynaklanmasını önlemek amacıyla her 3 yılda da verim sınırlandırımış ve eşitlenmiştir. Bu şekilde farkı yıllar içinde ve yıllar ortalamasında verim değerleri istatistiki olarak önemli bulunmamıştır. Ancak 2014 yılındaki olağan dışı yağışlardan kaynaklanan hastalık sorunu nedeniyle ve 2015 yılında şarjın daha yüksek olarak bırakılması nedeniyle yıllar arasında verim bakımından istatistiki farklııklar görülmektedir. 2015 yılı 8.96 kg/omca ile en yüksek ortalama verimin alındığı yıl olurken 2014 yılında verim 0.64 $\mathrm{kg} /$ omca olarak belirlenmiştir.

Deneme bölünmüş parseller deneme desenine göre 3 tekerrürlü olarak yürütülmüştür. Alınan verilere JMP 7.0.1 versiyonlu istatistik programında varyans analizi yapılmıştır. Varyans analizi sonucunda ana sürgün ve koltuk sürgünü uygulama interaksiyonu etkileri, ana sürgün ana etkisi (ASAE) ve koltuk sürgünü ana etkisi (KSAE) oluşmuştur. Çizelgelerde ana etkilerin ortalamaları LSD (0.05) çoklu karşılaştırma testi ile karşılaştırılmış, 3 yııı sonunda yıl birleştirmeleri ve istatistiki değerlendirmeleri yapılmıştır.

\section{Araştırmada İncelenen Kriterler}

Şırada endüstriyel olgunluğun belirlenmesi amacıyla; el tipi refraktometre (ATAGO Co. Ltd. Tokyo, Japan) ile SÇKM ( $\left.{ }^{\circ} \mathrm{Brix}\right) \%$ olarak; titrimetrik yöntemle tartarik asit cinsinden titre edilebilir asit (g/L) (Cemeroğlu, 2007) olarak belirlenmiştir. pH (Mettler Toledo FE20 marka dijital) pH metre ile ölçülmüştür. Bir gram üzüme düşen şeker miktarı (mg/g-tane), tanedeki şeker miktarının tane yaş ağırlığına bölünmesiyle hesaplanmıştır (Ferrer ve ark., 2014). Olgunluk göstergeleri; ${ }^{\circ} \mathrm{Brix} /$ Titre edilebilir asit, ve $\mathrm{pH}^{2} \times$ 'Brix değerleri Blouin ve Guimberteau (2000)'e göre hesaplanmış ve değerlendirilmiştir.

\section{BULGULAR ve TARTIŞMA}

\section{Tekirdağ ili iklim verileri}

Denemenin yürütüldüğü yıllarda vejetasyon periyodundaki etkili sıcaklık toplamları 2013 yılı için 2157.00 gün derece, 2014 yılı için 2074.64 gün derece ve 2015 yılı için 2142.00 gün derece olarak hesaplanmıştır. Tekirdağ ili için 19392017 yılları ortalaması ise 1887.00 gün derece'dir.

Tekirdağ yıllık toplam yağış miktarı 1939-2017 yılları için 581.10 mm'dir. 2013 yılı toplam yağışı 443.80 mm. 2014 yılı toplam yağış 770.50 ve 2015 yılında ise toplam yağış 507.90 mm olarak tespit edilmiştir (Anonim 2014; Anonim 2015; Anonim 2016).

Çalışmanın yürütüldüğü 3 yıl içinde 2014 yılı sıcaklık ve yağış miktarı yanında, güneşlenme şiddeti, oransal nem, rüzgar hızı gibi iklim özellikleri bakımından diğer iki yıldan ayrılmaktadır (Anonim, 2015).

\section{Suda çözünebilir kuru madde (SÇKM) (\%)}

Farklı koltuk sürgünü uzunluğu ve ana sürgün uzunluğu uygulamalarının suda çözünebilir kuru madde (SÇKM) üzerine etkileri ana sürgün ve koltuk sürgünü uygulamalarının ana etkilerinde 2013 yılı için $p<0.05$ düzeyinde önemli bulunmuştur. SÇKM miktarı bakımından "6-7 yaprak" ve "3-4 yaprak" uygulamalarının (sırasıyla \%22.85 ve \%22.65) en yüksek değere ulaştığı belirlenmiştir. "Yok" uygulamasının ise \%21.18 değeri ile son sırada yer aldığı saptanmıştır. Ana sürgün uzunluklarında "1.5 m" uygulaması \%22.56 ile en yüksek değerlere ulaşırken, "1.25 $\mathrm{m}^{\prime \prime}$ uygulaması \%22.23 ile diğer bir istatistiki grubu 
oluşturmuştur. "1 m" uygulaması \%21.90 SÇKM miktarı ile sonuncu sırada yer almıştır (Çizelge 1).

2014 yılında SÇKM üzerine etkiler koltuk sürgünü ana etkisi bakımından LSD \%5 düzeyinde önemli bulunmuş, \%20.84 ve \%20.66 suda çözünebilir kuru madde ile "3-4 yaprak" ve "67 yaprak" uygulamalarının daha düşük SÇKM miktarlarına Çizelge 1. Farklı yeşil budama uygulamalarının SÇKM üzerine etkileri (\%)

\begin{tabular}{|c|c|c|c|c|c|c|c|c|c|}
\hline \multirow{2}{*}{$\begin{array}{l}\text { Ana } \\
\text { sürgün } \\
\text { uygulaması }\end{array}$} & \multirow{2}{*}{$\begin{array}{l}\text { Koltuk } \\
\text { sürgünü } \\
\text { uygulaması }\end{array}$} & \multicolumn{2}{|l|}{2013} & \multicolumn{2}{|l|}{2014} & \multicolumn{2}{|l|}{2015} & \multicolumn{2}{|c|}{ Yıl birleştirme } \\
\hline & & $\begin{array}{l}\text { ASAE } \\
\text { ort. }\end{array}$ & $\begin{array}{l}\text { KSAE } \\
\text { ort. }\end{array}$ & $\begin{array}{l}\text { ASAE } \\
\text { ort. }\end{array}$ & KSAE ort. & $\begin{array}{l}\text { ASAE } \\
\text { ort. }\end{array}$ & $\begin{array}{l}\text { KSAE } \\
\text { ort. }\end{array}$ & $\begin{array}{l}\text { ASAE } \\
\text { ort. }\end{array}$ & $\begin{array}{l}\text { KSAE } \\
\text { ort. }\end{array}$ \\
\hline \multirow{3}{*}{$1 \mathrm{~m}$} & Yok & \multirow{3}{*}{$21.90 c$} & \multirow{3}{*}{$\begin{array}{l}21.18 b \\
\text { (Yok) }\end{array}$} & \multirow{3}{*}{20.97} & \multirow{3}{*}{$\begin{array}{l}21.31 a \\
\text { (Yok) }\end{array}$} & \multirow{3}{*}{22.42} & \multirow{3}{*}{$\begin{array}{l}22.42 b \\
\text { (Yok) }\end{array}$} & \multirow{3}{*}{$21.76 b$} & \multirow{3}{*}{$\begin{array}{l}21.6 \\
\text { (Yok) }\end{array}$} \\
\hline & 3-4 yaprak & & & & & & & & \\
\hline & 6-7 yaprak & & & & & & & & \\
\hline \multirow{3}{*}{$1.25 \mathrm{~m}$} & Yok & \multirow{3}{*}{$22.23 b$} & \multirow{3}{*}{$\begin{array}{l}22.65 a \\
\text { (3-4 ypr) }\end{array}$} & \multirow{3}{*}{20.97} & \multirow{3}{*}{$\begin{array}{l}20.84 b \\
\text { (3-4 ypr) }\end{array}$} & \multirow{3}{*}{22.80} & \multirow{3}{*}{$\begin{array}{l}22.86 a \\
(3-4 \mathrm{ypr})\end{array}$} & \multirow{3}{*}{$22.00 a$} & \multirow{3}{*}{$\begin{array}{l}22.12 a \\
\text { (3-4 ypr) }\end{array}$} \\
\hline & 3-4 yaprak & & & & & & & & \\
\hline & 6-7 yaprak & & & & & & & & \\
\hline \multirow{3}{*}{$1.5 \mathrm{~m}$} & Yok & \multirow{3}{*}{$22.56 a$} & \multirow{3}{*}{$\begin{array}{l}22.85 a \\
\text { (6-7 ypr) }\end{array}$} & \multirow{3}{*}{20.86} & \multirow{3}{*}{$\begin{array}{l}20.66 \text { b } \\
\text { (6-7 ypr) }\end{array}$} & \multirow{3}{*}{22.75} & \multirow{3}{*}{$\begin{array}{l}22.68 a b \\
\text { (6-7 ypr) }\end{array}$} & \multirow{3}{*}{$22.06 a$} & \multirow{3}{*}{$\begin{array}{l}22.07 \quad a \\
\text { (6-7 ypr) }\end{array}$} \\
\hline & 3-4 yaprak & & & & & & & & \\
\hline & 6-7 yaprak & & & & & & & & \\
\hline \multicolumn{2}{|c|}{ Yıllar ortalaması } & \multicolumn{2}{|l|}{$22.23 \mathrm{~B}$} & \multicolumn{2}{|l|}{$20.94 \mathrm{C}$} & \multicolumn{2}{|l|}{$22.65 \mathrm{~A}$} & --- & \\
\hline ASAE LSD 0.05 & & 0.299 & & Ö.D & & Ö.D & & 0.209 & \\
\hline KSAE LSD 0.05 & & 0.629 & & 0.383 & & 0.343 & & 0.342 & \\
\hline
\end{tabular}

Yıllar ortalaması $\mathrm{LSD}_{0.05} \quad 0.342$

2013 KSAE LSD $0.05: 0.629 ;$ ASAE LSD $0.05: 0.299 ; 2014$ KSAE LSD $0.05: 0.383 ; 2015$ KSAE LSD $0.05: 0.343 ;$ YIl birleştirme KSAE $\operatorname{LSD}_{0.05}: 0.342 ;$ ASAE LSD $0.05: 0.209 ;$ YIL LSD $_{0.05}=0.342$

ASAE: Ana sürgün uygulamaları ana etkisi (ortalaması); KSAE: Koltuk sürgünü uygulamaları ana etkisi (ortalaması).

Suda çözünebilir kuru madde üzerine 2015 yılında koltuk sürgünü uygulamaları için "3-4 yaprak" uygulamasında \%22.86 ile en yüksek değere ulaşırken, "6-7 yaprak" uygulaması \%22.68 ile diğer iki uygulamanın arasında yer bulmuştur. "Yok" uygulaması \%22.42 ile farklı bir istatistiki grubu oluşturmuştur. Ana sürgün uzunluğu uygulamalarının ana etkileri SÇKM miktarını istatistiki açıdan önemli ölçüde etkilememiş; “1.25 m" uygulaması \%22.80 ve "1.5 m" uygulaması \%22.75 SÇKM değerini vermiş; öte yandan "1 m" uygulaması \%22.42 değerini vermiştir (Çizelge 1).

Yıllar ortalamaları bakımından 2015 yılı \%22.65 ile en yüksek SÇKM görülen yıl olmuştur. 2013 yılında suda çözünebilir kuru madde \%22.23 seviyesine ulaşırken en düşük SÇKM birikimi \%20.94 ile 2014 yılında görülmüştür. Yıllar ortalamaları istatistiki bakımdan $p<0.05$ düzeyinde önemli bulunmuştur (Çizelge 1).

2013, 2014 ve 2015 yıllarının verileri birleştirilerek değerlendirildiğinde, koltuk sürgünü uygulamalarında "3-4 yaprak" ve "6-7 yaprak" uygulamaları \%22.12 ve \%22.07 SÇKM ile üst grubu oluştururken "Yok" uygulaması \%21.64 ile bir diğer istatistiki grubu meydana getirmiştir. Ana sürgün uzunluğu uygulamalarında ise " $1.5 \mathrm{~m}$ " ve " $1.25 \mathrm{~m}$ " uygulamaları \%22.02 ve \%22.00 SÇKM değerlerine ulaşırken, "1.5 m" uygulaması \%21.70 ile diğer istatistiki grubu oluşturmuştur (Çizelge 1). ulaştığı belirlenmiştir "Yok" uygulaması ise \%2131 miktarı ile en yüksek kuru madde birikimine ulaşmıştır. Farklı ana sürgün uzunlukları uygulamaları ise SÇKM miktarını istatistiki bakımdan önemli ölçüde etkilememiştir (Çizelge $1)$. 


\section{Titre edilebilir asit (TA) (g/L)}

Farklı sürgün uzunluğu uygulamalarının yaprak alma uygulamaları ana etkilerinin titre edilebilir asit üzerine etkileri istatistiki anlamda yalnızca 2014 yılında koltuk sürgünü uygulamalarında önemli olarak görülmektedir.

2014 yılında farklı koltuk sürgünü uzunluğu uygulamalarının TA üzerine etkileri koltuk sürgünü ana etkisinde $p<0.05$ düzeyinde önemli bulunmuştur. $7.80 \mathrm{~g} / \mathrm{L}$ ve $7.61 \mathrm{~g} / \mathrm{L}$ TA ile "6-7 yaprak" ve "3-4 yaprak" uygulamalarının daha yüksek TA miktarlarında kaldığı belirlenmiştir. "Yok" uygulaması ise $7.13 \mathrm{~g} / \mathrm{L}$ ile en düşük TA seviyesine ulaşmıştır. Farklı ana Çizelge 2. Farklı yeşil budama uygulamalarının titre edilebilir asit üzerine etkileri (g/L)

\begin{tabular}{|c|c|c|c|c|c|c|c|c|c|}
\hline \multirow{2}{*}{$\begin{array}{l}\text { Ana } \\
\text { sürgün } \\
\text { uygulaması }\end{array}$} & \multirow{2}{*}{$\begin{array}{l}\text { Koltuk } \\
\text { sürgünü } \\
\text { uygulaması }\end{array}$} & \multicolumn{2}{|l|}{2013} & \multicolumn{2}{|l|}{2014} & \multicolumn{2}{|l|}{2015} & \multicolumn{2}{|c|}{ Yıl birleştirme } \\
\hline & & $\begin{array}{l}\text { ASAE } \\
\text { ort. }\end{array}$ & $\begin{array}{l}\text { KSAE } \\
\text { ort. }\end{array}$ & $\begin{array}{l}\text { ASAE } \\
\text { ort. }\end{array}$ & KSAE ort. & $\begin{array}{l}\text { ASAE } \\
\text { ort. }\end{array}$ & $\begin{array}{l}\text { KSAE } \\
\text { ort. }\end{array}$ & $\begin{array}{l}\text { ASAE } \\
\text { ort. }\end{array}$ & $\begin{array}{l}\text { KSAE } \\
\text { ort. }\end{array}$ \\
\hline \multirow{3}{*}{$1 \mathrm{~m}$} & Yok & \multirow{3}{*}{5.85} & \multirow{3}{*}{$\begin{array}{l}5.96 \\
\text { (Yok) }\end{array}$} & \multirow{3}{*}{7.45} & \multirow{3}{*}{$\begin{array}{l}7.13 \text { b } \\
\text { (Yok) }\end{array}$} & \multirow{3}{*}{5.85} & \multirow{3}{*}{$\begin{array}{l}5.78 \\
\text { (Yok) }\end{array}$} & \multirow{3}{*}{6.38} & \multirow{3}{*}{$\begin{array}{l}6.29 \\
\text { (Yok) }\end{array}$} \\
\hline & 3-4 yaprak & & & & & & & & \\
\hline & 6-7 yaprak & & & & & & & & \\
\hline \multirow{3}{*}{$1.25 \mathrm{~m}$} & Yok & \multirow{3}{*}{5.83} & \multirow{3}{*}{$\begin{array}{l}5.85 \\
\text { (3-4 ypr) }\end{array}$} & \multirow{3}{*}{7.53} & \multirow{3}{*}{$\begin{array}{l}7.61 \text { a } \\
\text { (3-4 ypr) }\end{array}$} & \multirow{3}{*}{5.83} & \multirow{3}{*}{$\begin{array}{l}5.86 \\
\text { (3-4 ypr) }\end{array}$} & \multirow{3}{*}{6.40} & \multirow{3}{*}{$\begin{array}{l}6.42 \\
\text { (3-4 ypr) }\end{array}$} \\
\hline & 3-4 yaprak & & & & & & & & \\
\hline & 6-7 yaprak & & & & & & & & \\
\hline \multirow{3}{*}{$1.5 \mathrm{~m}$} & Yok & \multirow{3}{*}{5.93} & \multirow{3}{*}{$\begin{array}{l}5.80 \\
\text { (6-7 ypr) }\end{array}$} & \multirow{3}{*}{7.53} & \multirow{3}{*}{$\begin{array}{l}7.80 \text { a } \\
\text { (6-7 ypr) }\end{array}$} & \multirow{3}{*}{5.90} & \multirow{3}{*}{$\begin{array}{l}5.93 \\
\text { (6-7 ypr) }\end{array}$} & \multirow{3}{*}{6.46} & \multirow{3}{*}{$\begin{array}{l}6.52 \\
\text { (6-7 ypr) }\end{array}$} \\
\hline & 3-4 yaprak & & & & & & & & \\
\hline & 6-7 yaprak & & & & & & & & \\
\hline \multicolumn{2}{|c|}{ Yıllar ortalaması } & \multicolumn{2}{|l|}{$5,87 \mathrm{~B}$} & \multicolumn{2}{|l|}{$7,51 \mathrm{~A}$} & \multicolumn{2}{|l|}{$5,86 \mathrm{~B}$} & --- & \\
\hline ASAE LSD $_{0.05}$ & & Ö.D & & Ö.D & & Ö.D & & Ö.D & \\
\hline KSAE LSD 0.05 & & Ö.D & & 0.273 & & Ö.D & & Ö.D & \\
\hline Yıllar ortalam & SI LSD 0.05 & 0.378 & & & & & & & \\
\hline
\end{tabular}

2014 KSAE LSD 0.05 : 0.273; 2015 KSAE LSD 0.05 : 0.343; Yıl birleştirme YIL LSD $0.05=0.378$

ASAE: Ana sürgün uygulamaları ana etkisi(ortalaması); KSAE: Koltuk sürgünü uygulamaları ana etkisi (ortalaması).

Korkutal ve ark. (2017), koltuk yapraklarının asmadan tamamen çıkarılmasının toplam asitlik miktarını artırdığını bildirmiştir. Çalışmamızda 2013 yılında koltuk sürgünlerinin tamamen uzaklaştırıldığı "Yok" uygulamasında sayısal olarak benzer durum görülürken 2014 ve 2015 yıllarında ve tüm yılların ortalamasında "Yok" uygulamasının daha düşük TA değerine neden olduğu görülmektedir.

Sıcaklık ve tane kalitesi arasındaki en belirgin ilişkilerden biri, yüksek sıcaklıkların tanede organik asit konsantrasyonunu azaltmasıyla ortaya çıkar (Kliewer, 1973). Tane gelişiminin farklı aşamalarında organik asit birikimi ve parçalanması da farklı evrelerden geçer (Ford, 2012). Tartarik asit ve malik asitler tane gelişiminin tüm aşamalarına baskın organik asitler olup şıra asitliği ve $\mathrm{pH}$ üzerinde önemli etkilere neden olur (Morris ve ark., 1983). Özelikle malat ben düşme dönemine kadar tanede biriktirilerek olgunlaşma sürecinde ortaya çıkan karbon ihtiyacı için potansiyel bir kaynak olarak saklanır (Ruffner, 1982). Bu dönemde malik asidin harcanarak azalması toplam asitliği azaltarak şeker ve asit oranlarını dengeler (Kliewer, 1965). Bu durum denemenin yürütüldüğü yıllar sürgün uzunlukları uygulamalarının ise titre edilebilir asit değerlerini istatistiki bakımdan önemli ölçüde etkilemediği gözlenmiştir. "1.5 m" uygulaması $7.56 \mathrm{~g} / \mathrm{L}$ ile en yüksek TA seviyesinde kalırken, " 1.25 m" uygulaması $7.53 \mathrm{~g} / \mathrm{L}$ ve " $1 \mathrm{~m}$ " uygulaması $7.45 \mathrm{~g} / \mathrm{L}$ TA değerleri vermişlerdir (Çizelge 2). Yıllar ortalamaları incelendiğinde 2014 yılında $7.51 \mathrm{~g} / \mathrm{L}$ ile en yüksek TA değerinin ölçüldüğü görülmektedir. 2013 ve 2014 yıllarında titre edilebilir asit $5.87 \mathrm{~g} / \mathrm{L}$ ve $5.86 \mathrm{~g} / \mathrm{L}$ seviyelerine düşmüştür. Yıllar ortalamaları ana etkileri istatistiki açıdan önemli bulunmuştur (Çizelge 2). içinde en kurak yıl olan 2013 yılında koltuk sürgünlerinin tamamen uzaklaştırılmasının yüksek sıcaklıklar bakımından asmalarda etkin fotosentezin azalmasına neden olarak malik asitin karbon kaynağı olarak kullanımını azaltması ve dolayısıyla toplam asitliğin de yüksek kalmasına neden olması olarak yorumlanabilir.

Diğer yandan ana sürgün uzunluğundaki artış yıllar ortalamasında TA artışına da neden olmuştur. Yaşasın ve ark. (2014)'e göre ise istatistiki olarak önemli olmamakla birlikte ana sürgün uzunluğu artışı toplam asitliğin azalmasına neden olmaktadır.

\section{pH Değeri}

pH değerlerinin yalnızca 2014 yılında farklı ana ve koltuk sürgünü uzunlukları ana etkileri bakımından istatistiki olarak önemli olarak belirlenmiştir.

2014 yılında farklı koltuk sürgünü uzunluğu uygulamalarının $\mathrm{pH}$ üzerine etkileri koltuk sürgünü ana etkisinde $\mathrm{p}<0.05$ düzeyinde önemli bulunmuştur. "Yok" uygulaması $3.58 \mathrm{pH}$ ile en yüksek seviyeye ulaşırken, "3-4 yaprak" uygulaması 3.54 ve "6-7 yaprak" uygulaması 3.50 olarak ölçülmüş ve her uygulama farklı bir istatistiki grubu oluşturmuştur. 
CANDAR S, BAHAR E, KORKUTAL i, ALÇO T, GÜçLÜ M

Yıllar ortalamalarında 2014 yılı 3.54 ile en düşük pH görülen yıl olmuştur. 2013 ve 2014 yıllarında titre edilebilir asit 3.79 ve 3.75 seviyelerine düşmüştür. Yıllar ortalamaları istatistiki Çizelge 3. Farklı yeşil budama uygulamalarının $\mathrm{pH}$ üzerine etkileri

\begin{tabular}{|c|c|c|c|c|c|c|c|c|c|}
\hline \multirow{2}{*}{$\begin{array}{l}\text { Ana } \\
\text { sürgün } \\
\text { uygulaması }\end{array}$} & \multirow{2}{*}{$\begin{array}{l}\text { Koltuk } \\
\text { sürgünü } \\
\text { uygulaması }\end{array}$} & \multicolumn{2}{|l|}{2013} & \multicolumn{2}{|l|}{2014} & \multicolumn{2}{|l|}{2015} & \multicolumn{2}{|c|}{ Yıl birleştirme } \\
\hline & & $\begin{array}{l}\text { ASAE } \\
\text { ort. }\end{array}$ & $\begin{array}{l}\text { KSAE } \\
\text { ort. }\end{array}$ & $\begin{array}{l}\text { ASAE } \\
\text { ort. }\end{array}$ & KSAE ort. & $\begin{array}{l}\text { ASAE } \\
\text { ort. }\end{array}$ & $\begin{array}{l}\text { KSAE } \\
\text { ort. }\end{array}$ & $\begin{array}{l}\text { ASAE } \\
\text { ort. }\end{array}$ & $\begin{array}{l}\text { KSAE } \\
\text { ort. }\end{array}$ \\
\hline \multirow{3}{*}{$1 \mathrm{~m}$} & Yok & \multirow{3}{*}{3.85} & \multirow{3}{*}{$\begin{array}{l}3.90 \\
\text { (Yok) }\end{array}$} & \multirow{3}{*}{3.54} & \multirow{3}{*}{$\begin{array}{l}3.58 \text { a } \\
\text { (Yok) }\end{array}$} & \multirow{3}{*}{3.75} & \multirow{3}{*}{$\begin{array}{l}3.75 \\
\text { (Yok) }\end{array}$} & \multirow{3}{*}{3.71} & \multirow{3}{*}{$\begin{array}{l}3.74 \\
\text { (Yok) }\end{array}$} \\
\hline & 3-4 yaprak & & & & & & & & \\
\hline & 6-7 yaprak & & & & & & & & \\
\hline \multirow{3}{*}{$1.25 \mathrm{~m}$} & Yok & \multirow{3}{*}{3.74} & \multirow{3}{*}{$\begin{array}{l}3.84 \\
\text { (3-4 ypr) }\end{array}$} & \multirow{3}{*}{3.54} & \multirow{3}{*}{$\begin{array}{l}3.54 \text { b } \\
\text { (3-4 ypr) }\end{array}$} & \multirow{3}{*}{3.73} & \multirow{3}{*}{$\begin{array}{l}3.75 \\
\text { (3-4 ypr) }\end{array}$} & \multirow{3}{*}{3.67} & \multirow{3}{*}{$\begin{array}{l}3.65 \\
\text { (3-4 ypr) }\end{array}$} \\
\hline & 3-4 yaprak & & & & & & & & \\
\hline & 6-7 yaprak & & & & & & & & \\
\hline \multirow{3}{*}{$1.5 \mathrm{~m}$} & Yok & \multirow{3}{*}{3.79} & \multirow{3}{*}{$\begin{array}{l}3.65 \\
\text { (6-7 ypr) }\end{array}$} & \multirow{3}{*}{3.53} & \multirow{3}{*}{$\begin{array}{l}3.50 \text { c } \\
\text { (6-7 ypr) }\end{array}$} & \multirow{3}{*}{3.77} & \multirow{3}{*}{$\begin{array}{l}3.75 \\
\text { (6-7 ypr) }\end{array}$} & \multirow{3}{*}{3.70} & \multirow{3}{*}{$\begin{array}{l}3.70 \\
\text { (6-7 ypr) }\end{array}$} \\
\hline & 3-4 yaprak & & & & & & & & \\
\hline & 6-7 yaprak & & & & & & & & \\
\hline \multicolumn{2}{|c|}{ Yıllar ortalaması } & \multicolumn{2}{|l|}{$3.79 \mathrm{~A}$} & \multicolumn{2}{|l|}{$3.54 \mathrm{~B}$} & \multicolumn{2}{|l|}{$3.75 \mathrm{~A}$} & --- & \\
\hline ASAE LSD 0.05 & & Ö.D & & Ö.D & & Ö.D & & Ö.D & \\
\hline KSAE LSD 0.05 & & Ö.D & & 0.034 & & Ö.D & & Ö.D & \\
\hline Yıllar ortalan & ası $L_{S D} 0.05$ & 0.197 & & & & & & & \\
\hline
\end{tabular}

2014 KSAE LSD 0.05 : 0.034; Yıl birleştirme YIL LSD $0.05=0.197$

ASAE: Ana sürgün uygulamaları ana etkisi (ortalaması); KSAE: Koltuk sürgünü uygulamaları ana etkisi (ortalaması).

Çalışmada 2013 ve 2014 yıllarında koltuk sürgünü uygulamaları ana etkisindeki yaprak alanı azalmasıyla artan pH değerleri dikkati çekmektedir. 2014 yılındaki bu değişim istatistiki olarak da önemlidir. Diğer yandan sıra dışı yağışların görüldüğü 2014 yılında potasyum miktarlarındaki artışın pH değerlerindeki artışa etkisi olmaktadır. Koltuk sürgünü uygulamaları ve $\mathrm{pH}$ arasındaki bu ilişki yıllar ortalamasında ortaya çıkmasa da titre edilebilir asitlik, potasyum ve bunların bağlı olduğu yağış miktarı gibi değişkenler arasındaki ilişkiyi yansıtması bakımından önemlidir.

\section{Gram üzüme düşen şeker miktarı ( $\mathrm{mg} / \mathrm{g}$-tane)}

Bir gram taneye düşen şeker miktarı üzerine farklı sürgün uzunluklarının etkilerinin SÇKM etkileriyle paralel seyir izlediği görülmektedir. 2013 yılında farklı koltuk sürgünü

Çizelge 4. Farklı yeşil budama uygulamalarının bir gram üzüme düşen şeker miktarı üzerine etkileri (mg/g-tane)

\begin{tabular}{|c|c|c|c|c|c|c|c|c|c|}
\hline \multirow{2}{*}{$\begin{array}{l}\text { Ana } \\
\text { sürgün } \\
\text { uygulaması }\end{array}$} & \multirow{2}{*}{$\begin{array}{l}\text { Koltuk } \\
\text { sürgünü } \\
\text { uygulaması }\end{array}$} & \multicolumn{2}{|c|}{2013} & \multicolumn{2}{|c|}{2014} & \multicolumn{2}{|c|}{2015} & \multicolumn{2}{|c|}{ Yıl birleştirme } \\
\hline & & ASAE ort. & $\begin{array}{c}\text { KSAE } \\
\text { ort. }\end{array}$ & $\begin{array}{l}\text { ASAE } \\
\text { ort. }\end{array}$ & KSAE ort. & $\begin{array}{l}\text { ASAE } \\
\text { ort. }\end{array}$ & $\begin{array}{c}\text { KSAE } \\
\text { ort. }\end{array}$ & $\begin{array}{l}\text { ASAE } \\
\text { ort. }\end{array}$ & $\begin{array}{c}\text { KSAE } \\
\text { ort. }\end{array}$ \\
\hline \multirow{3}{*}{$1 \mathrm{~m}$} & Yok & \multirow{3}{*}{$164.41 \mathrm{c}$} & \multirow{3}{*}{$\begin{array}{c}158.11 \text { b } \\
\text { (Yok) }\end{array}$} & \multirow{3}{*}{156.22} & \multirow{3}{*}{$\begin{array}{c}159.15 \text { a } \\
\text { (Yok) }\end{array}$} & \multirow{3}{*}{169.00} & \multirow{3}{*}{$\begin{array}{c}169.03 \text { b } \\
\text { (Yok) }\end{array}$} & \multirow{3}{*}{$\begin{array}{c}163.21 \\
b\end{array}$} & \multirow{3}{*}{$\begin{array}{c}162.09 \text { b } \\
\text { (Yok) }\end{array}$} \\
\hline & 3-4 yaprak & & & & & & & & \\
\hline & 6-7 yaprak & & & & & & & & \\
\hline \multirow{3}{*}{$1.25 \mathrm{~m}$} & Yok & \multirow{3}{*}{$167.35 \mathrm{~b}$} & \multirow{3}{*}{$\begin{array}{l}171.10 \text { a } \\
\text { (3-4 ypr) }\end{array}$} & \multirow{3}{*}{156.22} & \multirow{3}{*}{$\begin{array}{l}155.05 \text { b } \\
\text { (3-4 ypr) }\end{array}$} & \multirow{3}{*}{172.40} & \multirow{3}{*}{$\begin{array}{l}172.96 \mathrm{a} \\
\text { (3-4 ypr) }\end{array}$} & \multirow{3}{*}{$\begin{array}{c}165.32 \\
a\end{array}$} & \multirow{3}{*}{$\begin{array}{l}166,37 \text { a } \\
\text { (3-4 ypr) }\end{array}$} \\
\hline & 3-4 yaprak & & & & & & & & \\
\hline & 6-7 yaprak & & & & & & & & \\
\hline \multirow{3}{*}{$1.5 \mathrm{~m}$} & Yok & \multirow{3}{*}{ 170. 29 a } & \multirow{3}{*}{$\begin{array}{l}172.85 \text { a } \\
\text { (6-7 ypr) }\end{array}$} & \multirow{3}{*}{155.26} & \multirow{3}{*}{$\begin{array}{l}153.48 \text { b } \\
\text { (6-7 ypr) }\end{array}$} & \multirow{3}{*}{171.99} & 171.40 & \multirow{3}{*}{$\begin{array}{c}165.84 \\
a\end{array}$} & \multirow{3}{*}{$\begin{array}{l}165.91 \mathrm{a} \\
\text { (6-7 ypr) }\end{array}$} \\
\hline & 3-4 yaprak & & & & & & $a b$ & & \\
\hline & 6-7 yaprak & & & & & & (6-7 ypr) & & \\
\hline \multicolumn{2}{|c|}{ Yıllar ortalaması } & \multicolumn{2}{|c|}{$167.35 \mathrm{~A}$} & \multicolumn{2}{|c|}{$155.90 \mathrm{C}$} & \multicolumn{2}{|c|}{$171.13 \mathrm{~A}$} & \multicolumn{2}{|c|}{$\begin{array}{ll}-- \\
--\end{array}$} \\
\hline ASAE LSD 0.05 & & 2.6 & & & & & $\mathrm{D}$ & & 366 \\
\hline KSAE LSD $_{0.05}$ & & 5.6 & & & & & 76 & & 35 \\
\hline Yıllar ortalam & sI LSD 0.05 & & & & 3.03 & & & & \\
\hline
\end{tabular}

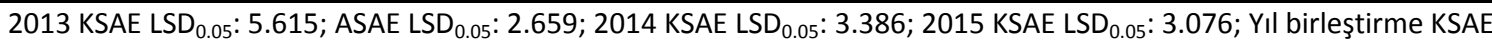
$\operatorname{LSD}_{0.05}: 3.035 ;$ ASAE LSD $0.05: 1.866$; YIL LSD $0.05=3.035$

ASAE: Ana sürgün uygulamaları ana etkisi (ortalaması); KSAE: Koltuk sürgünü uygulamaları ana etkisi (ortalaması). uzunluğu ve ana sürgün uzunluğu uygulamalarının bir gram üzüme düşen şeker miktarı üzerine etkileri ana sürgün ana etkisi ve koltuk sürgünü ana etkisi konularında $p<0.05$ düzeyinde önemli bulunmuştur (Çizelge 4). $172.85 \mathrm{mg} / \mathrm{g}$ tane ve 171.14 mg/g-tane şeker miktarı ile "6-7 yaprak" ve "3-4 yaprak" uygulamalarının en yüksek bir gram üzüme düşen şeker miktarlarına ulaştığı belirlenmiştir. "Yok" Ana sürgün uygulamaları ana etkileri istatistiki bakımdan $p<$ 0.05 düzeyinde önemlidir. " $1.5 \mathrm{~m}$ " uygulaması $170.29 \mathrm{mg} / \mathrm{g}$ tane ile en yüksek değerlere ulaşırken, " 1.25 m” uygulaması $167.35 \mathrm{mg} / \mathrm{g}$-tane ile diğer bir istatistiki grubu oluşturmuştur. "1 m" uygulaması $164.41 \mathrm{mg} / \mathrm{g}$-tane şeker miktarı ile sonuncu sırada yer almıştır. uygulaması ise $158.11 \mathrm{mg} / \mathrm{g}$-tane ile son sırada yer almıştır.

ASAE: Ana sürgün uygulamaları ana etkisi (ortalamasi); KSAE: Koltuk sürgünü uygulamalari ana etkisi (ortalamasI). 
2014 yılında $153.48 \mathrm{mg} / \mathrm{g}$-tane ve $155.05 \mathrm{mg} / \mathrm{g}$-tane şeker miktarı ile "6-7 yaprak" ve "3-4 yaprak" uygulamalarının daha düşük şeker miktarlarına ulaştığı belirlenmiştir. "Yok" uygulaması ise $159.15 \mathrm{mg} / \mathrm{g}$-tane ile en yüksek şeker miktarı birikimine ulaşmıştır. 2014 yılında farklı koltuk sürgünü uzunluğu uygulamalarının bir gram üzüme düşen şeker miktarı üzerine etkileri koltuk sürgünü ana etkisi bakımından $p<0.05$ düzeyinde önemli bulunmuştur. Farklı ana sürgün uzunlukları uygulamaları ana etkileri bir gram üzüme düşen şeker miktarını istatistiki açıdan önemli ölçüde etkilememiştir (Çizelge 4).

2015 yılında benzer şekilde "3-4 yaprak" uygulaması 172.96 mg/g-tane ile en yüksek şeker miktarına ulaşırken, "6-7 yaprak" uygulaması $171.40 \mathrm{mg} / \mathrm{g}$-tane ile diğer iki uygulamanın arasında yer bulmuştur. "Yok" uygulaması $169.03 \mathrm{mg} / \mathrm{g}$-tane ile farklı bir istatistiki grubu oluşturmuştur. Ana sürgün uygulamaları ana etkisi ise bir gram üzüme düşen şeker miktarını istatistiki bakımdan önemli ölçüde etkilememiştir.

Yıllar ortalamaları bakımından 2015 yılında 171.13 mg/gtane ile en yüksek şeker miktarlarının görüldüğü yıl olmuştur. 2013 yılında bir gram üzüme düşen şeker miktarı $167.55 \mathrm{mg} / \mathrm{g}$-tane seviyesine ulaşırken en düşük şeker miktarı 155.90 mg/g-tane ile 2014 yılında görülmüştür (Çizelge 4).
Son yıllarda hasat zamanına karar verirken şeker konsantrasyonu yerine tanedeki şeker miktarının ölçümü tercih edilmekte ve daha net sonuçlar elde edilmektedir (Bahar ve ark., 2018). Bir gram üzüme düşen şeker miktarı ise tanedeki şeker miktarının tane yaş ağırlığına bölünerek tanedeki her bir grama denk gelen şeker miktarının mg cinsinden olarak ifadesidir. 2013 ve 2015 yıllarına benzer iklim özellikleri gösteren yıllarda yapılan farklı çalışmalarda (Hunter, 1997; Bahar ve ark., 2018) koltuk yapraklarının tane şeker miktarını yükselttiği ifade edilmiştir. Bununla birlikte SÇKM seviyelerinde olduğu gibi 2014 yılında koltuk yapraklarının tamamının alındığı "Yok" uygulaması gram üzüme düşen şeker miktarı konusunda öne çıkmıştır.

\section{Olgunluk indisi ( ${ }^{\circ} \mathrm{Brix} / \mathrm{Titre}$ edilebilir asit)}

İlgili kriter bakımından yalnızca 2014 yılının farklı koltuk sürgünü uzunluğu uygulamalarının ${ }^{\circ}$ Brix / titre edilebilir asit üzerine etkileri koltuk sürgünü ana etkisinde LSD 0.05 düzeyinde önemli bulunmuştur. 26.50 ve 27.40 oranları ile "6-7 yaprak" ve "3-4 yaprak" uygulamalarının daha düşük değerler oluşturduğu belirlenmiştir. 2014 yılında "Yok" uygulaması ise 29.80 ile en yüksek değere ulaşmıştır. Ana sürgün uzunlukları ana etkileri ise bu değerleri istatistiki bakımdan önemli ölçüde etkilememiştir. "1 $\mathrm{m}$ " uygulaması $28.20 \mathrm{~g} / \mathrm{L}$ ile en yüksek oranlarda kalırken, "1.25 m" uygulaması 27.90 ve "1.5 m" uygulaması 27.60 oranlarına ulaşmışlardır (Çizelge 5).

Çizelge 5. Farklı yeşil budama uygulamalarının ${ }^{\circ}$ Brix / titre edilebilir asit üzerine etkileri

\begin{tabular}{|c|c|c|c|c|c|c|c|c|c|}
\hline \multirow{2}{*}{$\begin{array}{l}\text { Ana } \\
\text { sürgün } \\
\text { uygulaması }\end{array}$} & \multirow{2}{*}{$\begin{array}{l}\text { Koltuk } \\
\text { sürgünü } \\
\text { uygulaması }\end{array}$} & \multicolumn{2}{|l|}{2013} & \multicolumn{2}{|l|}{2014} & \multicolumn{2}{|l|}{2015} & \multicolumn{2}{|c|}{ Yıl birleştirme } \\
\hline & & $\begin{array}{l}\text { ASAE } \\
\text { ort. }\end{array}$ & $\begin{array}{l}\text { KSAE } \\
\text { ort. }\end{array}$ & $\begin{array}{l}\text { ASAE } \\
\text { ort. }\end{array}$ & KSAE ort. & $\begin{array}{l}\text { ASAE } \\
\text { ort. }\end{array}$ & $\begin{array}{l}\text { KSAE } \\
\text { ort. }\end{array}$ & $\begin{array}{l}\text { ASAE } \\
\text { ort. }\end{array}$ & $\begin{array}{l}\text { KSAE } \\
\text { ort. }\end{array}$ \\
\hline \multirow{3}{*}{$1 \mathrm{~m}$} & Yok & \multirow{3}{*}{37.80} & \multirow{3}{*}{$\begin{array}{l}3.57 \\
\text { (Yok) }\end{array}$} & \multirow{3}{*}{28.20} & \multirow{3}{*}{$\begin{array}{l}29.80 \text { a } \\
\text { (Yok) }\end{array}$} & \multirow{3}{*}{38.30} & \multirow{3}{*}{$\begin{array}{l}38.80 \\
\text { (Yok) }\end{array}$} & \multirow{3}{*}{34.80} & \multirow{3}{*}{$\begin{array}{l}34.80 \\
\text { (Yok) }\end{array}$} \\
\hline & 3-4 yaprak & & & & & & & & \\
\hline & 6-7 yaprak & & & & & & & & \\
\hline \multirow{3}{*}{$1.25 \mathrm{~m}$} & Yok & \multirow{3}{*}{38.60} & \multirow{3}{*}{$\begin{array}{l}3.94 \\
\text { (3-4 ypr) }\end{array}$} & \multirow{3}{*}{27.90} & \multirow{3}{*}{$\begin{array}{l}27.40 \text { b } \\
\text { (3-4 ypr) }\end{array}$} & \multirow{3}{*}{39.10} & \multirow{3}{*}{$\begin{array}{l}39.00 \\
\text { (3-4 ypr) }\end{array}$} & \multirow{3}{*}{35.20} & \multirow{3}{*}{$\begin{array}{l}35.30 \\
\text { (3-4 ypr) }\end{array}$} \\
\hline & 3-4 yaprak & & & & & & & & \\
\hline & 6-7 yaprak & & & & & & & & \\
\hline \multirow{3}{*}{$1.5 \mathrm{~m}$} & Yok & \multirow{3}{*}{38.20} & \multirow{3}{*}{$\begin{array}{l}3.94 \\
\text { (6-7 ypr) }\end{array}$} & \multirow{3}{*}{27.60} & \multirow{3}{*}{$\begin{array}{l}26.50 \text { b } \\
\text { (6-7 ypr) }\end{array}$} & \multirow{3}{*}{38.60} & \multirow{3}{*}{$\begin{array}{l}38.30 \\
\text { (6-7 ypr) }\end{array}$} & \multirow{3}{*}{34.80} & \multirow{3}{*}{$\begin{array}{l}34.70 \\
\text { (6-7 ypr) }\end{array}$} \\
\hline & 3-4 yaprak & & & & & & & & \\
\hline & 6-7 yaprak & & & & & & & & \\
\hline \multicolumn{2}{|c|}{ Yıllar ortalaması } & \multicolumn{2}{|l|}{$38.20 \mathrm{~A}$} & \multicolumn{2}{|l|}{$27.90 \mathrm{~B}$} & \multicolumn{2}{|l|}{$38.70 \mathrm{~A}$} & --- & \\
\hline ASAE $L^{2} D_{0.05}$ & & Ö.D & & Ö.D & & Ö.D & & Ö.D & \\
\hline KSAE LSD 0.05 & & Ö.D & & 0.121 & & Ö.D & & Ö.D & \\
\hline Yıllar ortalan & ASI LSD 0.05 & 0.272 & & & & & & & \\
\hline
\end{tabular}

2014 KSAE LSD $0.05: 1.21 ;$ Yll birleştirme YIL LSD $0.05=2.72$

ASAE: Ana sürgün uygulamaları ana etkisi (ortalaması); KSAE: Koltuk sürgünü uygulamaları ana etkisi (ortalaması).

Yıllar ortalamaları bakımından 2013 ve 2015 yılları 38.70 ve 38.20 ile en yüksek ${ }^{\circ}$ Brix / titre edilebilir asit oranlarının görüldüğü yıllar olmuştur. 2014 yılında ${ }^{\circ}$ Brix / titre edilebilir asit oranı 27.90 olarak hesaplanmıştır. Yıllar ortalamaları istatistiki bakımdan LSD \%5 düzeyinde önemli bulunmuştur (Çizelge 5).

Ideal ${ }^{\circ}$ Brix / titre edilebilir asit oranı aralığı Blouin ve Guimberteau (2000) tarafından 30-40 olarak ifade edilmiştir. 2014 yılı hariç diğer yıllarda ve farklı ana ve koltuk sürgünü uygulamalarında bu değerlerin yakalandığı görülmektedir. 2014 yılı koltuk sürgünü uygulamaları ana etkileri dışından istatistiki olarak önemli etkiler görülmemekle beraber şÇKM ve gram üzüme düşen şeker miktarı kriterlerinde olduğu gibi koltuk sürgünü uygulamalarının yılın iklimine bağlı olarak farklı tepkiler verdiği görülmektedir. Koltuk sürgünlerinde yapılacak düzenlemelerle olgunluğu az miktarda da olsa erkene almak ya da geciktirmek en azından rakamsal ifadelerle olası gözükmektedir.

\section{$\mathrm{pH}^{2} \times{ }^{\circ}$ Brix}

2014 yılı dışında farklı koltuk sürgünü uzunluğu ve ana sürgün uzunluğu uygulamalarının $\mathrm{pH}^{2} \times{ }^{\circ}$ Brix değerleri 
üzerine etkilerinin değişimleri istatistiki olarak önemli bulunmamıştır.

2014 yılında farklı koltuk sürgünü uzunluğu uygulamalarının $\mathrm{pH}^{2} \times{ }^{\circ}$ Brix üzerine etkileri koltuk sürgünü ana etkisinde $\mathrm{p}<$ 0.05 düzeyinde önemli bulunmuştur. 273.52 değeri ile en yüksek $\mathrm{pH}^{2} \times{ }^{\circ} \mathrm{Brix}$ "Yok" uygulaması için hesaplanmış olup, "3-4 yaprak" uygulaması 261.90 ve "6-7 yaprak" uygulaması Çizelge 6. Farklı yeşil budama uygulamalarının $\mathrm{pH}^{2} \times{ }^{\circ}$ Brix üze
CANDAR S, BAHAR E, KORKUTAL i, ALÇO T, GÜçLÜ M 253.52 olmuş ve her bir uygulama farklı istatistiki sınıfları ifade etmişlerdir. Farklı ana sürgün uzunlukları uygulamalarının $\mathrm{pH}^{2} \times{ }^{\circ}$ Brix değerlerini istatistiki açıdan önemli ölçüde etkilemediği gözlenmiştir. " $1 \mathrm{~m}$ " uygulaması 264.38 ile en yüksek $\mathrm{pH}^{2} \times{ }^{\circ}$ Brix / seviyesine ulaşırken; “1.25 $\mathrm{m}$ " uygulaması 263.26 ve " $1 \mathrm{~m}$ " uygulaması 261.31 olarak hesaplanmıştır (Çizelge 6).

\begin{tabular}{|c|c|c|c|c|c|c|c|c|c|}
\hline \multirow{2}{*}{$\begin{array}{l}\text { Ana } \\
\text { sürgün } \\
\text { uygulaması }\end{array}$} & \multirow{2}{*}{$\begin{array}{l}\text { Koltuk } \\
\text { sürgünü } \\
\text { uygulaması }\end{array}$} & \multicolumn{2}{|l|}{2013} & \multicolumn{2}{|l|}{2014} & \multicolumn{2}{|l|}{2015} & \multicolumn{2}{|c|}{ Yıl birleştirme } \\
\hline & & $\begin{array}{l}\text { ASAE } \\
\text { ort. }\end{array}$ & $\begin{array}{l}\text { KSAE } \\
\text { ort. }\end{array}$ & $\begin{array}{l}\text { ASAE } \\
\text { ort. }\end{array}$ & KSAE ort. & $\begin{array}{l}\text { ASAE } \\
\text { ort. }\end{array}$ & $\begin{array}{l}\text { KSAE } \\
\text { ort. }\end{array}$ & $\begin{array}{l}\text { ASAE } \\
\text { ort. }\end{array}$ & $\begin{array}{l}\text { KSAE } \\
\text { ort. }\end{array}$ \\
\hline \multirow{3}{*}{$1 \mathrm{~m}$} & Yok & \multirow{3}{*}{324.63} & \multirow{3}{*}{$\begin{array}{l}323.85 \\
\text { (Yok) }\end{array}$} & \multirow{3}{*}{264.38} & \multirow{3}{*}{$\begin{array}{l}273.52 \mathrm{a} \\
\text { (Yok) }\end{array}$} & \multirow{3}{*}{310.01} & \multirow{3}{*}{$\begin{array}{l}315.78 \\
\text { (Yok) }\end{array}$} & \multirow{3}{*}{301.67} & \multirow{3}{*}{$\begin{array}{l}304.38 \\
\text { (Yok) }\end{array}$} \\
\hline & 3-4 yaprak & & & & & & & & \\
\hline & 6-7 yaprak & & & & & & & & \\
\hline \multirow{3}{*}{$1.25 \mathrm{~m}$} & Yok & \multirow{3}{*}{316.05} & \multirow{3}{*}{$\begin{array}{l}302.45 \\
\text { (3-4 ypr) }\end{array}$} & \multirow{3}{*}{263.26} & \multirow{3}{*}{$\begin{array}{l}261.91 \text { b } \\
\text { (3-4 ypr) }\end{array}$} & \multirow{3}{*}{317.99} & \multirow{3}{*}{$\begin{array}{l}322.52 \\
\text { (3-4 ypr) }\end{array}$} & \multirow{3}{*}{299.10} & \multirow{3}{*}{$\begin{array}{l}295.63 \\
\text { (3-4 ypr) }\end{array}$} \\
\hline & 3-4 yaprak & & & & & & & & \\
\hline & 6-7 yaprak & & & & & & & & \\
\hline \multirow{3}{*}{$1.5 \mathrm{~m}$} & Yok & \multirow{3}{*}{327.16} & \multirow{3}{*}{$\begin{array}{l}341.54 \\
\text { (6-7 ypr) }\end{array}$} & \multirow{3}{*}{261.31} & \multirow{3}{*}{$\begin{array}{l}253.52 \text { с } \\
\text { (6-7 ypr) }\end{array}$} & \multirow{3}{*}{324.53} & \multirow{3}{*}{$\begin{array}{l}320.22 \\
\text { (6-7 ypr) }\end{array}$} & \multirow{3}{*}{304.33} & \multirow{3}{*}{$\begin{array}{l}305.09 \\
\text { (6-7 ypr) }\end{array}$} \\
\hline & 3-4 yaprak & & & & & & & & \\
\hline & 6-7 yaprak & & & & & & & & \\
\hline \multicolumn{2}{|c|}{ Yıllar ortalaması } & \multicolumn{2}{|l|}{$322.61 \mathrm{~A}$} & \multicolumn{2}{|l|}{$262.98 \mathrm{~B}$} & \multicolumn{2}{|l|}{$319.51 \mathrm{~A}$} & --- & \\
\hline ASAE $L^{2} D_{0.05}$ & & Ö.D & & Ö.D & & Ö.D & & & Ö.D \\
\hline KSAE LSD 0.05 & & Ö.D & & 8.036 & & Ö.D & & & Ö.D \\
\hline Yıllar ortalam & SI LSD 0.05 & 33.184 & & & & & & & \\
\hline
\end{tabular}

ASAE: Ana sürgün uygulamaları ana etkisi (ortalaması); KSAE: Koltuk sürgünü uygulamaları ana etkisi (ortalaması).

Yıllar ortalamaları bakımından 2013 ve 2015 yılları 322.61 ve 319.51 değerleri ile en yüksek $\mathrm{pH}^{2} \times{ }^{\circ}$ Brix değerinin görüldüğü yıllar olmuştur. 2014 yıllarında $\mathrm{pH}^{2} \times{ }^{\circ} \mathrm{Brix} 262.98$ olarak hesaplanmıştır. Yıllar ortalamaları istatistiki bakımdan LSD \%5 düzeyinde önemli bulunmuştur. Koltuk sürgünü ve ana sürgün uygulamalarının ana etkileri ise istatistiki açıdan önemli değildir (Çizelge 6).

$\mathrm{pH}^{2} \times{ }^{\circ}$ Brix olgunluk indisine göre 260 değerinin üzerinde taneler tam olgunluğa ulaşmaktadır (Blouin ve Guimberteau, 2000). Her üç yılda ve tüm uygulamalarda bu göstergeye göre; olgunluğa ulaşıldığı görülmektedir. Uygulamalar arasındaki farklar düşük ve istatistiki olarak önemsiz olmakla birlikte farklı taç yönetimi teknikleriyle olgunluk seviyesinde ufak değişimler yaratılabildiği belirlenmiştir. Yıllar arasındaki iklim farklılıklarına bağlı olarak 2014 yılında "Yok" uygulamasının bu olgunluk göstergesinde de diğer uygulamalardan rakamsal olarak ayrıldığı görülmektedir.

SONUÇ

Olgunluk göstergelerinin incelenmesi sonucunda uygulamalar arasındaki farklar düşük ve istatistiki olarak önemsiz olmakla birlikte farklı taç yönetimi teknikleriyle olgunluk seviyesinde ufak değişimler yaratılabildiği belirlenmiştir. 2013 ve 2015 yıllarında olduğu gibi vejetasyon döneminde yağışın az, oransal nemin nispeten düşük ve sıcaklıkların yüksek olduğu yetiştirme dönemlerinde 3-4 yapraklı koltuk sürgünü uygulamasının olgunluğu bir miktar erkene almasından söz edilebilir. 2014 yılında ise benzer etki "Yok" uygulamasında görülmektedir. Ana sürgün uzunluğu uygulamalarının endüstriyel olgunluk ve olgunluk göstergeleri ile ilgili kesin etkilerinden söz etmek olası değildir. Dolayısıyla, olgunluğa müdahale etmek için yapılacak olan yeşil budama uygulamalarının özellikle ben düşme döneminden sonra yılın iklim karakterine ve ulaşılmak istenen hedef ürüne göre planlamasıyla olabileceği düşünülmektedir.

\section{KAYNAKLAR}

Anonim (2007) Climate Change 2007. Synthesis Report. Contribution of Working Groups I, II and III to the Fourth Assessment Report of the Intergovernmental Panel on Climate Change, Geneva, Switzerland. 104p.

Anonim (2013) Summary for Policymakers. in: Climate Change 2013: The Physical Science Basis. Contribution of Working Group I to the $5^{\text {th }}$ Assessment Report of the Intergovernmental Panel on Climate Change. Cambridge University Press, Cambridge, UK and New York, NY, USA.

Anonim (2014) 2013 Yılı İklim Değerlendirmesi. www.mgm.gov.tr/files/iklim/2013-yili-iklimdegerlendirmesi.pdf Erişim tarihi: 10.11.2016.

Anonim (2015) 2014 Yılı İklim Değerlendirmesi. www.mgm.gov.tr/FILES/iklim/2014-yili-iklimdegerlendirmesi.pdf Erişim tarihi: 10.11.2016.

Anonim (2016) Tekirdağ ili genel istatistik verileri. https://www.mgm.gov.tr/veridegerlendirme/ililceleri statistik.aspx?k=A\&m=TEKIRDAG8 Erişim tarihi: 10.11.2016.

Bahar E, Korkutal i, Tekin D (2012) Küresel Isınmanın Bağcılık Üzerine Etkileri. Trakya University Journal of Engineering Sciences 13(1): 1-15.

Bahar E, Korkutal i, Öner H (2018) Cabernet-Sauvignon Üzüm Çeşidinde Farklı Kültürel İşlemlerin Şıra 
Özellikleri Üzerine Etkileri. Selcuk Journal of Agriculture and Food Sciences 32(1): 1-7.

Blouin J, Guimberteau G (2000) Maturation et Maturite des Raisins. Feret, Bordeaux, ISBN: 2-902416-49-0

Bock A, Sparks T, Estrella N, Menzel A (2011) Changes in the Phenology and Composition of Wine from Franconia Germany. Climate Research 50: 69-81.

Cemeroğlu B (2007) Gıda Analizleri. Gıda Teknolojisi Derneği Yayınları, 657s, Ankara.

Chuine I, Yiou P, Viovy N, Seguin B, Daux V, Ladurie E (2004) Historical Phenology: Grape Ripening as a Past Climate Indicator. Nature 432: 289-290

Dalla Marta A, Grifoni D, Mancini M, Storchi P, Zipoli G, Orlandini S (2010) Analysis of the Relationships Between Climate Variability and Grapevine Phenology in the Nobile di Montepulciano Wine Production Area. The Journal of Agricultural Science 148(06): 657-666.

Daux V, Garcia de Cortazar-Atauri I, Yiou P, Chuine I, Garnier E, Le Roy Ladurie, Mestre E, Tardagaulia J (2012) An Open-Database of Grape Harvest Dates for Climate Research: Data Description and Quality Assessment. Climate of the Past 8, 1403-1418.

Ferrer M, Echeverría G, Carbonneau A (2014) Effect of Berry Weight and Its Components on the Contents of Sugars and Anthocyanins of Three Varieties of Vitis vinifera $\mathrm{L}$. Under Different Water Supply Conditions. South African Journal of Enology and Viticulture 35(1): 103113.

Ford CM (2012) The Biochemistry of Organic Acids in the Grape. The Biochemistry of the Grape Berry. Bentham Science Publishers. 22: 67-88.

Godden P, Gishen M (2005) Trends in the Composition of Australian Wine. The Australian and New Zealand Wine Industry Journal 20(5): 21-46. DOI: 10.1111/ajgw.12195

Hunter JJ (1997) Implications of Seasonal Canopy Management and Growth Compensation in Grapevine. South African Journal of Enology and Viticulture 21(2): 81-91.

Jones GV, White MA, Cooper OR, Storchmann K (2005) Climate Change and Global Wine Quality. Climatic Change 73(3): 319-343.

Korkutal i, Bahar E (2013) Influence of Different Soil Tillage and Leaf Removal Treatments on Yield, Cluster and Berry Characteristics in cv. Syrah (Vitis vinifera L.). Bulgarian Journal of Agricultural Science 19: 652-663.

Korkutal I, Bahar E, Bayram S (2017) Farklı Toprak İşleme ve Yaprak Alma Uygulamalarının Syrah Üzüm Çeşidinde Su Stresi, Salkım ve Tane Özellikleri Üzerine Etkileri. Ege Üniversitesi Ziraat Fakültesi Dergisi 54(4): $397-$ 407.

Kliewer WM (1965) Changes in The Concentration of Malates, Tartrates, and Total Free Acids in Flowers and Berries of Vitis vinifera. American Journal of Enology and Viticulture 16: 92-100.
Kliewer WM (1973) Berry Composition of Vitis vinifera Cultivars as Influenced by Photo Temperatures and Nycto-Temperatures During Maturation. Journal of the American Society for Horticultural Science 98: 153-159.

Lorenz D, Eichhorn K, Bleiholder H, Klose R, Meier U, Weber E. (1995) Phenological Growth Stages of the Grapevine (Vitis vinifera L. ssp. vinifera)-Codes and Descriptions According to the Extended BBCH Scale. Australian Journal of Grape and Wine Research 1:100110.

Morris JR, Sims CA, Cawthon DL (1983) Effects of Excessive Potassium Levels on $\mathrm{pH}$, Acidity and Color of Fresh and Stored Grape Juice. American Journal of Enology and Viticulture 34: 35-39.

Olsen JL, Olesen A, Breuning-Madsen H, Balstrom T (2011) A Method to Identify Potential Cold-Climate Vine Growing Sites - A Case Study From Rosnaes in Denmark. Danish Journal of Geography 111: 73-84.

Palliotti A, Panara F, Silvestroni O, Lanari V, Sabbatini P, Howell GS, Gatti M, Poni, S (2013) Influence of Mechanical Postveraison Leaf Removal Apical to Cluster Zone on Delay of Fruit Ripening in Sangiovese (Vitis vinifera L.) Grapevines. Australian Journal of Grape and Wine Research 19: 369-377.

Parker AK, Raw V, Martin D, Haycock S, Sherman E, Trought MCT (2016) Reduced Grapevine Canopy Size PostFlowering via Mechanical Trimming Alters Ripening and Yield of Pinot noir. Vitis 55: 1-9.

Petrie, PR, Sadras VO (2008) Advancement of Grapevine Maturity in Australia Between 1993 and 2006: Putative Causes, Magnitude of Trends and Viticultural Consequences. Australian Journal of Grape and Wine Research 14: 33-45.

Poni S, Gatt M, Bernizzoni F, Civardi S, Bobeica N, Magnanini E, Palliotti A (2013) Late Leaf Removal Aimed at Delaying Ripening in cv. Sangiovese: Physiological Assessment and Vine Performance. Australian Journal of Grape and Wine Research 19: 378-387.

Ruffner HP (1982) Metabolism of Tartaric and Malic Acids in Vitis - A Review. Part B. Vitis 21: 346-358.

Sadras VO, Petrie PR (2011) Climate Shifts in South-Eastern Australia: Early Maturity of Chardonnay, Shiraz and Cabernet-Sauvignon is Associated with Early Onset Rather Than Faster Ripening. Australian Journal of Grape and Wine Research 17: 199-205.

Türkeş M (2002) İlim Değişikliği Türkiye-Iklim Değişikliği Çerçeve Sözleşmesi İlişkileri ve İklim Değişikliği Politikaları http://www.tubitak.gov.tr Erişim Tarihi: 18.03.2013.

Vrsic S, Vodovnik T (2012) Reactions of Grape Varieties to Climate Changes in North East Slovenia. Plant Soil and Environment 58: 34-41.

Webb LB, Whetton PH, Barlow EWR (2008) Climate Change and Winegrape Quality in Australia. Climate. Research. 36: 99-111. 
Webb LB, Whetton PH, Barlow EWR (2011) Observed Trends in Winegrape Maturity in Australia. Global Change Biology 17: 2707-2719.

Yaşasın AS, Boz Y, Avcı GG, Gündüz A, Gülcü $M$, Kiracı MA, Bahar E (2014) Cabernet-Sauvignon Üzüm Çeşidinde Farklı Toprak İşleme ve Sürgün Uzunluğu Uygulamalarının Su Stresi, Verim ve Kalite Kriterleri Üzerine Etkileri. TAGEM Proje Sonuç Raporu. Tekirdağ Bağcılık Araştırma Enstitüsü. Mart 2014.
Zoecklein BW, Wolf TK, Duncannw, Judge JM, Cook MK (1992) Effects of Fruit Zone Leaf Removal on Yield, Fruit Composition and Fruit Rot Incidande of Chardonnay and White Riesling Grapes (Vitis vinifera L.). American Journal of Enology and Viticulture 43(2): 139-148. 
